\title{
Non-Specific Protein Adsorption on Polyetheretherketones -Challenges for Application as Biomaterial
}

\author{
Habil Svea Petersen* \\ Fakultät Ingenieurwissenschaften und Informatik, Hochschule Osnabrück, Germany \\ *Corresponding author: Habil Svea Petersen, Fakultät Ingenieurwissenschaften und Informatik, Labor für Chemie und \\ Oberflächenmodifikation, Hochschule Osnabrück, Germany
}

\begin{abstract}
This work deals with the investigation of the non-specific protein adsorption on polyetheretherketones (PEEK). As this polymer has positive characteristics like high comparable mechanical properties to bone and bio-inertness, it is more and more used as implant material in orthopaedics and dentistry. However, non-specific protein adsorption to PEEK has not been investigated in detail and can be a challenge for surface bioconjugation, as one method to enhance bone-PEEK contact. Here, we analysed and compared the influence of different PEEK-surfaces, modified via plasma- and wet-chemical processes. First, the surfaces of the various modified PEEK films were characterized regarding surface properties. In addition, the protein adsorption on differently modified films was quantified at the model of bovine serum albumin via an adapted protein assay. Striking is the comparison of contact angle measurement with the protein adsorption, evidencing higher protein adsorption with increased hydrophobicity of PEEK surfaces. The pure PEEK-film is extremely hydrophobic and shows the highest protein loading. Chemically treated films show a slightly lower contact angle and also a slightly decreased protein adsorption, while the plasma treated films, show a very low contact angle immediately after modification and a very low protein adsorption. However, in another measurement after 14 day of storage a significant increase in protein adsorption and contact angle was recognized. This result clarifies how PEEK surface modification affects non-specific protein adsorption.
\end{abstract}

Keywords: High performance polymers; Non-specific protein adsorption; Surface modification; Biomaterial

\section{Introduction}

By the late 1990s, polyetheretherketone (PEEK) turned into a promising polymeric alternative to metal implant components, particularly in orthopedic and traumatic applications [1]. In the course of recent years, PEEK has furthermore pulled in a lot of enthusiasm from dental technologists and dentists. Besides aesthetics, fundamental main trust is given by PEEKs incredible biomechanical properties. In its natural form, the Young's modulus of PEEK is around 3.6GPa, being more comparable to the elasticity of cortical bone as nowadays used metal alternatives [2,3]. Moreover, PEEK shows great biocompatibility in vitro and in vivo, causing neither toxic or mutagenic effects nor clinically significant inflammation [4,5]. However, PEEK is biologically inert [6,7], which has constrained its potential applications. One noteworthy methodology for the improvement of PEEK regarding improved bioactivity is surface modification. For application in dentistry and orthopedics specific addressing of osteoblasts in terms of proliferation is conceivable by bio functionalisation. While current PEEK modification for the promotion of osseointegration foresee the surface coating or bulk modification with calcium phosphate or hydroxy lapatite, a further possibility could be the long- or shortterm immobilization of bone morphogenetic protein 2 (BMP-2) [8]. However, non-specific adsorption to PEEK might possibly lead to denaturation and thereby to a loss of function of BMP-2 during the immobilization process. Moreover, non-specific protein adsorption is not only a challenge during bio immobilization processes but also the initiator of all foreign body reactions, in the worst case leading to an encapsulation of the biomaterial. Due to this reason, we here focus on the investigation of non-specific protein adsorption on PEEK. We included one plasma- and two chemically modified PEEK 
surfaces in order to account for the influence of different surface compositions. Plasma treatment of PEEK has been demonstrated with various modifications [9-11] in order to obtain significant changes in the surface properties as increase in surface energy [12], creation of functional groups or influence on cell growth cell growth [13]. However, non-specific protein adsorption on plasma-modified PEEK has not been addressed in literature so far. Regarding chemical modification of PEEK, we decided to investigate two processes, which we considered convenient for biomedical application. The first approach by Noiset et al. [14,15] is a three step process starting with the reduction of the keto groups of the benzophenone repeating units of the PEEK polymer backbone, followed by the attachment of hexamethylene diisocyanate (HMDI) under formation of PEEK-NCO and finishing with hydrolyzation of isocyanate groups yielding PEEK- $\mathrm{NH}_{2}$. The second chemical process, published by Becker et al. [16], is a facile technique for the wet-chemical amination of PEEK achieved by the formation of a Schiff base using ethylene diamine (EDA). The influence of these modifications on non-specific protein adsorption is also not known today. In this context, we prepared and characterized air-plasma treated, HMDI and EDA-modified PEEK-surfaces regarding surface chemistry, amine group density, surface topography and water contact angle. Subsequently, non-specific protein adsorption was quantified at the model of bovine serum albumin via an adapted protein assay.

\section{Materials and Methods}

\section{Materials}

As model substrate PEEK films (VESTAKEEP 4000G, thickness approx. $0.5 \mu \mathrm{m}$ ) were kindly provided by Evonik Industries AG. For later modification, PEEK specimen with a diameter of $600 \mathrm{~mm}^{2}$ were cut and then cleaned with isopropanol. Bovine serum albumin served as model protein and was purchased from Sigma Aldrich, Munich, Germany.

\section{Surface modification}

\section{a) Low pressure plasma treatment of PEEK}

The plasma treatment is carried out with HPT-100 machine of Henniker Plasma. The time is programmed to 180 s at a pressure of $0.2 \mathrm{mbar}$ and a power of $80 \mathrm{~W}$, then the plasma treatment is stopped, and the chamber is ventilated. The vacuum pump system is the "Duo 1.6" rotary pump from Pfeiffer Vacuum, Air is used as the process gas.

\section{b) Modification of PEEK using HMDI}

In order to obtain a modification of the surface of PEEK by means of HMDI, the method of Noiset is applied. In the first step, PEEK is modified to PEEK-OH. Therefore, $250 \mathrm{ml}$ of dimethyl sulphoxide (DMSO) and $0.5 \mathrm{~g}$ of $\mathrm{NaBH}_{4}$ are heated to $120{ }^{\circ} \mathrm{C}$ with constant stirring in a three-necked round bottom flask. The PEEK film is added to the liquid for 3 hours and should be completely wetted. This is followed by five washes. First, the PEEK is placed in methanol for 15 minutes and then in distilled water for 10 minutes, in $0.5 \mathrm{M}$ hydrochloric acid for 10 minutes, in distilled water for 10 minutes, and finally in ethanol for 10 minutes. Afterwards the
PEEK samples are dried overnight in a vacuum drying oven at 60 ${ }^{\circ} \mathrm{C}$ and $1 \mathrm{mbar}$. In the second step, PEEK-OH is modified to PEEKNCO. Therefore, $250 \mathrm{ml}$ of dry toluene, $12.5 \mathrm{ml}$ of HMDI and $0.026 \mathrm{~g}$ of DABCO are placed in a three-neck round bottom flask. The PEEK$\mathrm{OH}$ sample is added to the solution and wetted completely with the solution. The container is sealed airtight and filled with gaseous argon. The reaction proceeds within the reaction vessel over a period of 3 days at room temperature. After the 3 days the samples are cleaned for 20 minutes under argon atmosphere in dry toluene and then in dry acetone. In the third step PEEK-NCO is modified to PEEK- $\mathrm{NH}_{2}$. For this purpose, $125 \mathrm{ml}$ of 0.5 molar sodium hydroxide solution $(\mathrm{NaOH})$ are added to a flask, followed by immersing the PEEK-NCO sample for 5 hours. This is followed by three washes of distilled water for 10 minutes and a wash of acetone for 5 minutes. The PEEK- $\mathrm{NH}_{2}$ sample is dried in a vacuum drying oven at $60^{\circ} \mathrm{C}$ and 1 mbar overnight.

\section{c) Modification of PEEK by Means of EDA}

In order to modify PEEK by means of EDA, the PEEK film is completely immersed in the EDA according to Becker's method. The PEEK is modified to PEEK- $\mathrm{NH}_{2}$. The PEEK sample is cleaned with distilled water and degreased with isopropanol. Thereafter the sample is placed in pure EDA and treated at a temperature of $120{ }^{\circ} \mathrm{C}$ for 4 hours with stirring. Finally, the sample is dipped in isopropanol to clean it and dried in a vacuum oven $\left(60^{\circ} \mathrm{C} / 1 \mathrm{mbar}\right)$ overnight.

\section{d) Non-Specific Protein Adsorption on PEEK}

In order to perform the non-specific protein adsorption on PEEK, a BSA solution of $1 \mathrm{mg} / \mathrm{ml}$ ) in phosphate buffered saline (PBS buffer, $\mathrm{pH} 7,2$ ) is prepared. PEEK samples with a diameter of $6 \mathrm{~mm}$ are cut out of the modified samples, placed in a vial and completely wetted with $50 \mu \mathrm{l}$ of protein solution for 24 hours at $37^{\circ} \mathrm{C}$. After this procedure the samples are dried in a vacuum oven overnight.

\section{Characterization of PEEK Surfaces}

\section{a) Fourier-transform infrared spectroscopy}

FTIR ATR spectrometry on FTIR-ATR Avatar, Thermo Nicolet, was performed with the aim of characterizing chemical surface modification. The individual sample surfaces are each subjected to 32 scans in a wavenumber range of $400 \mathrm{~cm}^{-1}$ to $4000 \mathrm{~cm}^{-1}$.

\section{b) Amino group detection}

The sulfo-SDTB method is a straightforward procedure using sulfo-succinimidyl-4-0-(4,4-dimethoxytrityl) butyrate (s-SDTB) to determine amino groups on matrixes. Therefore, samples are shaken continuously for 40 minutes at room temperature in $1 \mathrm{ml}$ of a $0.5 \mathrm{mmol}$ sodium bicarbonate buffer solution and $1 \mathrm{ml} 0.06 \%$ s-SDTB solution in dimethylformamide. In this process the s-SDTB is covalently bonded to the surface $\mathrm{NH}_{2}$-group. To subsequently remove remains of the S-SDTB the samples are rinsed twice with ultrapure water. Finally the samples are placed in $1 \mathrm{ml}$ of $70 \%$ perchloric acid and shaken for 15 minutes. In this case the dimethoxytrityl cation is cleaves from the previously sulfoSDTB-modified amine groups. In addition, two untreated PEEK 
samples are treated by this procedure to obtain blank values. In the microplate reader of the company BMG Labtech with the type designation "FluoSTAR", $300 \mu$ of this solution are measured regarding absorption at $494 \mathrm{~nm}$. Based on the molar extinction coefficient of $70,000 \mathrm{M}^{-1} \mathrm{~cm}^{-1}$, the exact concentration of the reacted sulfo. SDTB is determined correlating to concentration of amine groups.

\section{c) Scanning electron microscope (SEM)}

For surface topography examination of the samples, the scanning electron microscope ZEISS AURIGIA was used with a magnification of 500 .

\section{d) Contact angle measurement}

Films to be measured are placed on the measuring surface of the contact angle measuring device OCA 20 from DATAPHYSICS. Seven water droplets $(10 \mu \mathrm{l})$ are added to each surface in order to determine the contact angle on a the zoomed-in image. This test procedure is performed immediately after surface modification. For plasma-treated surfaces the characterization is repeated after 14 days.

\section{e) Quantification of Non-Specific Protein Adsorption}

The amount of protein BSA adsorbed to PEEK surfaces is quantified by means of a colorimetric assay. For this experiment the Thermo Scientific Micro Bicinchronic Acid (BCA) Assay Kit was used. For calibration, BSA concentrations of 200, 160, 120, 80, 40, 20, 10, 5 and $1 \mathrm{mg} / \mathrm{ml}$ in PBS are prepared. $25 \mu \mathrm{l}$ of each concentration are added to a well of a 96 microplate and stored at $40{ }^{\circ} \mathrm{C}$ overnight. During that time the PBS evaporates. Then $300 \mu$ l of the working reagent prepared according to manufacturers' instruction for the BCA assay are added to each sample and incubated for 2 hours at $37^{\circ} \mathrm{C}$. Finally, $250 \mu \mathrm{l}$ of the previous $300 \mu \mathrm{l}$ are pipetted into a new well and measured by means of absorption spectroscopy at a wavelength of $562 \mathrm{~nm}$. To measure non-specific protein adsorption, PEEK samples are placed in wells and treated as described for calibration.

\section{Results and Discussion}

\section{Surface chemistry of differently modified peek surfaces}

The reference spectrum (PEEK (Reference)) shows all characteristic vibrations bands for PEEK caused by the following contained functional group:

i) ketone at $1647 \mathrm{~cm}^{-1}$;

ii) ether at $1221 \mathrm{~cm}^{-1}$ and $834 \mathrm{~cm}^{-1}$ and

iii) aromatic rings at $1593 \mathrm{~cm}^{-1}$ and $1466 \mathrm{~cm}^{-1}$ (Figures 1-5).

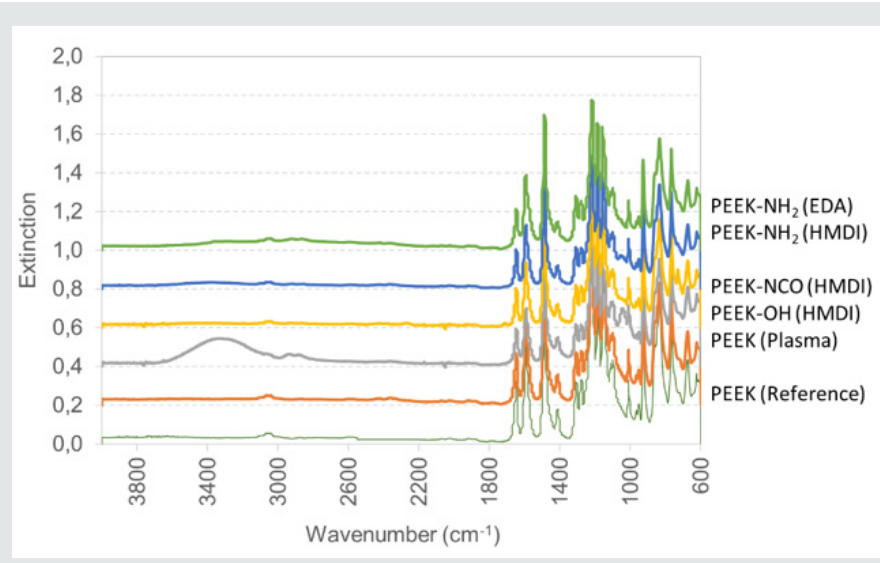

Figure 1: FTIR-ATR spectra of differently modified PEEK surfaces: PEEK (Reference), PEEK-OH (HMDI), PEEK-NCO (HMDI),

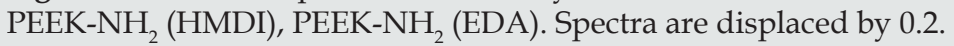

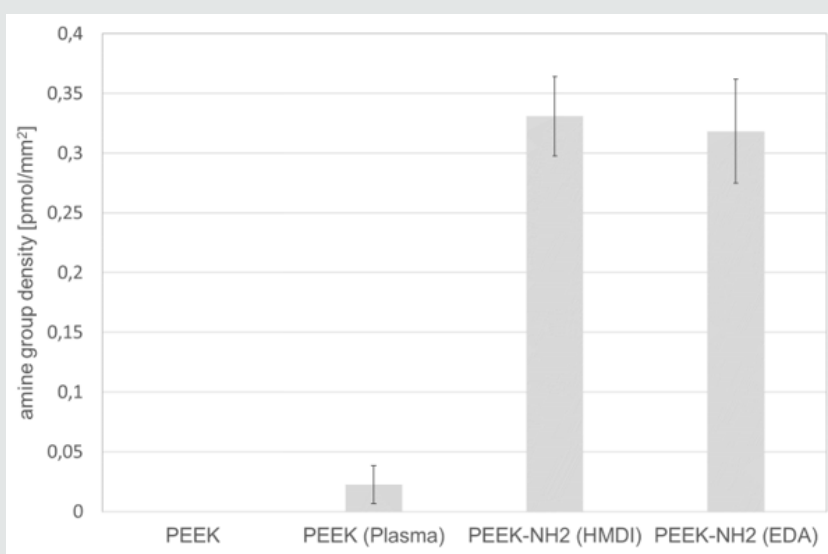

Figure 2: Amine group density on differently modified PEEK surfaces: PEEK (Reference), PEEK (Plasma), PEEK-NH ${ }_{2}\left(\mathrm{HMDI}_{\text {), }}\right.$ PEEK-NH $\mathrm{N}_{2}$ (EDA) as determined via the sulfo-SDTB method. Bars represent mean values \pm standard deviation of 5 replicate measurements. 


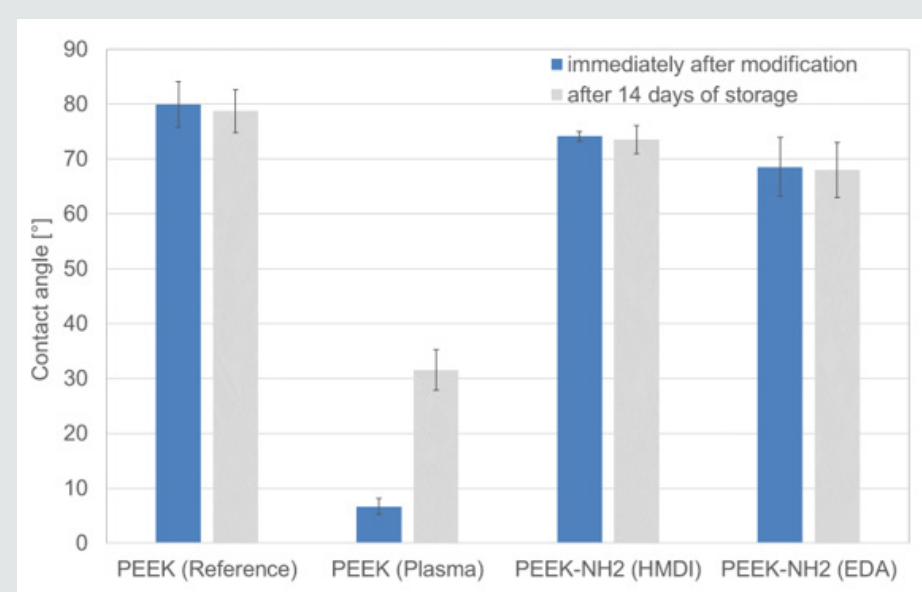

Figure 3: Water contact angle on differently modified PEEK surfaces: PEEK (Reference), PEEK (Plasma), PEEK-NH 2 (HMDI), PEEK-NH $\mathrm{N}_{2}$ (EDA) immediately after modification and after 14 days of storage. Bars represent mean values \pm standard deviation of 5 replicate measurements.
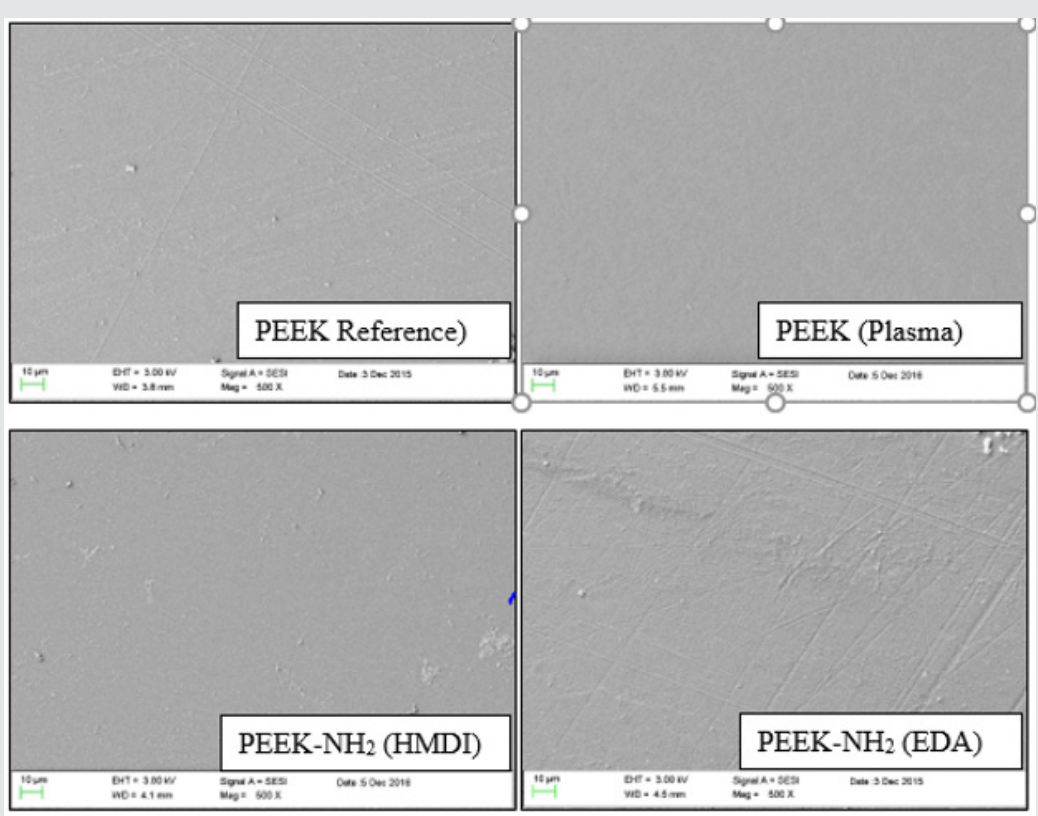

Figure 4: Scanning electron micrographs of differently modified PEEK surfaces with a magnification of 500: PEEK (Reference), PEEK (Plasma), PEEK-NH 2 (HMDI), PEEK-NH2 (EDA).

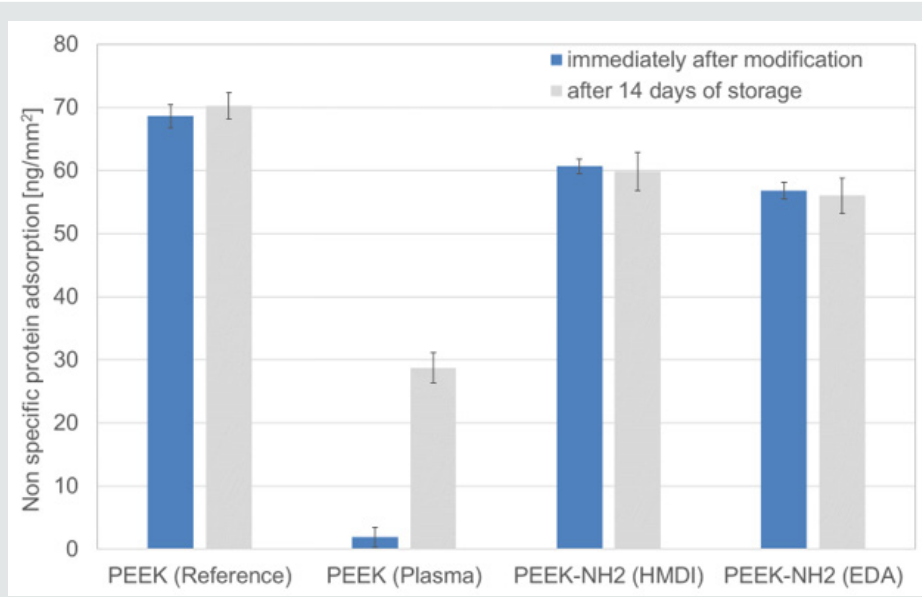

Figure 5: Non-specific protein adsorption on differently modified PEEK surfaces PEEK: (Reference), $\mathrm{PEEK}_{\text {(Plasma), } \mathrm{PEEK} \mathrm{NH}} \mathrm{P}_{2}$ (HMDI), PEEK-NH $\mathrm{NH}_{2}$ (EDA), as determined for BSA as model protein via quantification by means of a BCA Assay immediately after modification and after 14 days of storage. Bars represent mean values \pm standard deviation of 5 replicate measurements. 
Compared to the untreated PEEK, the spectrum of plasma treated PEEK shows exactly the same characteristic bands. This is probably due to the fact of the low penetration depth of plasma modification causing low abundance of functional groups not exceeding the detection limit of FTIR. The chemically modified PEEK surface via HMDI shows an additional broad band at $3328 \mathrm{~cm}$ ${ }^{1}$ after the first reaction step to PEEK-OH (HMDI), indicating the presence of $\mathrm{OH}$ groups. In the spectrum of the second step of HMDI modification, this band disappears, evidencing successful reaction of hydroxyl group. The NCO band is however not visible, probably due to the low abundancy of functional groups and high detection limit of the FTIR. In contrast, the spectrum of the third and last reaction step to PEEK- $\mathrm{NH}_{2}$ (HMDI) shows a broad band at $3400 \mathrm{~cm}^{-1}$ indicating the presence of amines. Spectrum of EDA-modified PEEK (PEEK-NH $\mathrm{N}_{2}$ (EDA)) has a similar appearance. All results are in well accordance to literature $[15,16]$.

\section{Amine Group Density on Differently Modified PEEK Surfaces}

No amine groups are detected on untreated PEEK surfaces in accordance to the molecular structure. The air-plasma treated PEEK surfaces (PEEK (Plasma) evidence a low amine group density of $0.022 \pm 0.016 \mathrm{pmol} / \mathrm{mm}^{2}$. From literature it is known that air plasma treatment mainly leads to the generation of hydroxyl and further oxygen-containing groups. The detected amine groups are side reaction, probably introduced via the nitrogen contained in air. In contrast to the air plasma treatment, both chemical reaction directly aim at the generation of amine groups. The amine group density underlines this assumption. The HMDI modified films have the highest amine group density of $0.331 \pm 0.033 \mathrm{pmol} / \mathrm{mm}^{2}$, directly followed by the EDA-modified PEEK surfaces with an amine group density of $0.318 \pm 0.016 \mathrm{pmol} / \mathrm{mm}^{2}$.

\section{Water contact angle on differently modified peek surfaces}

The water contact angle on unmodified PEEK surfaces is $80^{\circ}$. In comparison to all other modifications, this is the highest contact angle evidencing the hydrophobic property of PEEK. The lowest water contact angle is detected on air plasma treated PEEK with a very low value of $7^{\circ}$ This shows the potency of plasma treatments for the generation of hydrophilic surfaces. In contrast, the HMDI- and EDA-modified PEEK surfaces evidence a contact angle of $74^{\circ}$ and $68^{\circ}$, respectively. Both surfaces have a comparable amine group density, which is significantly higher than on plasma-treated PEEK surfaces. Therefore, amine groups are not the predominant factor defining hydrophilicity, it is more likely that the incorporation of oxygen containing groups during air plasma treatment is responsible. Amine groups on PEEK only lead to a small decrease of the water contact angle compared to untreated surfaces. Moreover, EDAmodified PEEK surfaces evidence a slightly lower hydrophobicity than HMDI-modified surfaces because of the shorter alkyl chain. Noticeable is furthermore that the water contact angle is stable on both chemically treated surfaces, while it increases on the plasma treated surfaces from 7 to $32^{\circ}$ after 14 days of storage. This is in accordance to literature, reporting instability of plasma treated surfaces due to the rearrangement of polymer chains.

\section{Surface topography of differently modified peek surfaces}

Scanning electron micrographs of differently treated PEEK surfaces show no difference in comparison to the untreated surfaces, evidencing that no damage of roughening of the PEEK surfaces occurred during the treatments. Furthermore, this fact proves that all detected differences on non-specific protein adsorption are likely due to differences in surface composition.

\section{Non-specific protein adsorption to differently modified peek surfaces}

Untreated PEEK, although being bioinert, shows the highest non-specific protein adsorption among the differently modified PEEK surfaces investigated. In correlation to the water contact angle measurements, it can be clearly seen that the untreated PEEK surface is also the most hydrophobic. Thus, one could conclude that hydrophobicity enormously contributes to non-specific protein adsorption. This is underlined by the fact that air-plasma treated PEEK surfaces evidence the lowest protein loading, correlating to the low hydrophobicity. Both chemically modified PEEK surfaces have a slightly lower protein loading compared to untreated PEEK surfaces, which is again in accordance with the determined tendency of the water contact angles. Only the plasma-treated surfaces show time dependent protein loading. After 14 days of storage reduction of non-specific protein adsorption is still obvious but less present than immediately after modification. Again, correlation with the water contact angle, which also increases with storage time for plasma-treated surfaces, is noticed.

\section{Conclusion}

By reported results, we conclude that non-specific protein adsorption on PEEK is mainly strengthened via hydrophobic interactions. In other terms, increasing the hydrophilicity of the surface decreases non-specific protein adsorption to PEEK, which is known for further biomaterials as for example polylactides $[17,18]$, but has not been reported for PEEK before. Hence, plasma modification can be used for the preparation of PEEK for bio immobilization processes, which however have to take place immediately after plasma activation to account for the instability of plasma-modified surfaces. Amine group density, if afforded for bio immobilization, could be increased using ammonia as process gas [19]. The well reported and here investigated chemical modification processes of PEEK indeed lead to enhanced amine group densities. However, non-specific protein adsorption is not reduced significantly compared to untreated PEEK.

\section{Acknowledgements}

The authors acknowledge the technical support of Veronika Terveen, Hannelore Schmidt, Marius Barth and Katharina Mey, who assisted during the analytical and of the study. Moreover, the provision of PEEK from Evonik Materials is appreciated.

\section{References}

1. Kurtz SM, Devine JN (2007) PEEK Biomaterials in Trauma, Orthopedic, and Spinal Implants. Biomaterials 28: 4845-4869. 
2. Godara A, Raabe D, Green S (2007) The influence of sterilization processes on the micromechanical properties of carbon fiber-reinforced PEEK composites for bone implant applications. Acta Biomater 3: 209220.

3. Williams D (2008) Polyetheretherketone for long-term implantable devices. Med Device Technol 19(8): 10-11.

4. Nieminen T, Kallela I, Wuolijoki E, Kainulainen H, Hiidenheimo I (2008) Amorphous and crystalline polyetheretherketone: Mechanical properties and tissue reactions during a 3-year follow-up. J Biomed Mater Res A 84: 377-383.

5. Wenz LM, Merritt K, Brown SA, Moet A, Steffee AD (1990) In vitro biocompatibility of polyetheretherketone and polysulfone composites. J Biomed Mater Res 24: 207-215.

6. Briem D, Strametz S, Schröder K, Meenen NM (2005) Response of primary fibroblasts and osteoblasts to plasma treated polyetheretherketone (PEEK) surfaces. J Mater Sci Mater Med 16: 671-677.

7. Wang H, Xu M, Zhang W, Kwok DTK, Jiang J, et al. (2010) Mechanical and biological characteristics of diamond-like carbon coated poly aryl-etherether-ketone. Biomaterials 31: 8181-8187.

8. Ponader S (2009) In-vitro - und In-vivo Untersuchungen zur Biofunktionalisierung von Knochenersatzmaterialien. In vitro and in vivo performance of biofunctionalized bone grafts.

9. Henneuse Boxus C, Poleunis C, De Ro A, Adriaensen Y, Bertrand P (1999) Surface functionalization of PEEK films studied by time-of-flight secondary ion mass spectrometry and x-ray photoelectron spectroscopy. Surface and Interface Analysis 27: 142-152.

10. Chu PK, Lu X (2015) Low Temperature Plasma Technology: Methods and Applications. CRC Press.
11. Stöhr U (2015) Oberflächenaktivierung von Kunststoff mittels Plasma zur Haftvermittlung. Vakuum in Forschung und Praxis 27: 16-21.

12. Inagaki N, Tasaka S, Horiuchi T, Suyama R (1998) Surface modification of poly (aryl ether ether ketone) film by remote oxygen plasma. Journal of Applied Polymer Science 68: 271-279.

13. Schröder K, Meyer-Plath A, Keller D, Ohl A (2002) On the applicability if plasma-assisted chemical micropatterning to different polymeric biomaterials. Plasmas and Polymers 7: 103-125.

14. Noiset O, Schneider YJ, Marchand Brynaert J (1999) Fibronectin adsorption or/and covalent grafting on chemically modified PEEK film surfaces. J Biomater Sci Polym Ed 10: 657-677.

15. Noiset O, Schneider YJ, Marchand Brynaert J (1997) Surface modification of poly (aryl ether ether ketone) (PEEK) film by covalent coupling of amines and amino acids through a spacer arm. J Polym Sci A Polym Chem 35: $3779-3790$.

16. Becker M, Lorenz S, Strand D, Vahl CF, Gabriel M (2013) Covalent Grafting of the RGD-Peptide onto Polyetheretherketone Surfaces via Schiff Base Formation. The Scientific World Journal.

17. Petersen S, Strohbach A, Busch R, Felix S, Schmitz K (2013) Siteselective immobilization of anti-CD34 antibodies to poly(L-lactide) for endovascular implant surfaces. Journal of Biomedical Materials Research Part B: Applied Biomaterials 102: 345-355.

18. Lima MVS, Duek EAR, Santana CC (2009) Adsorption of human immunoglobulin $G$ to poly ( $\beta$-hydroxybutyrate) (PHB), poly ( $\mathrm{L}$ - lactic Acid) (PLLA) and PHB/PLLA blends. Brazilian Journal of Chemical Engineering 26: 257-264.

19. Krüger P (2000) Plasmamodifizierung von Kunststoffen und Aspekte der industriellen Umsetzung. Vakuum in Forschung und Praxis 12: 231234 .

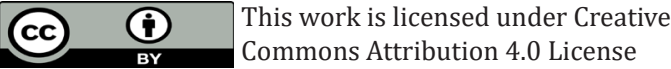

To Submit Your Article Click Here: Submit Article

DOI: 10.32474/MAMS.2019.01.000119

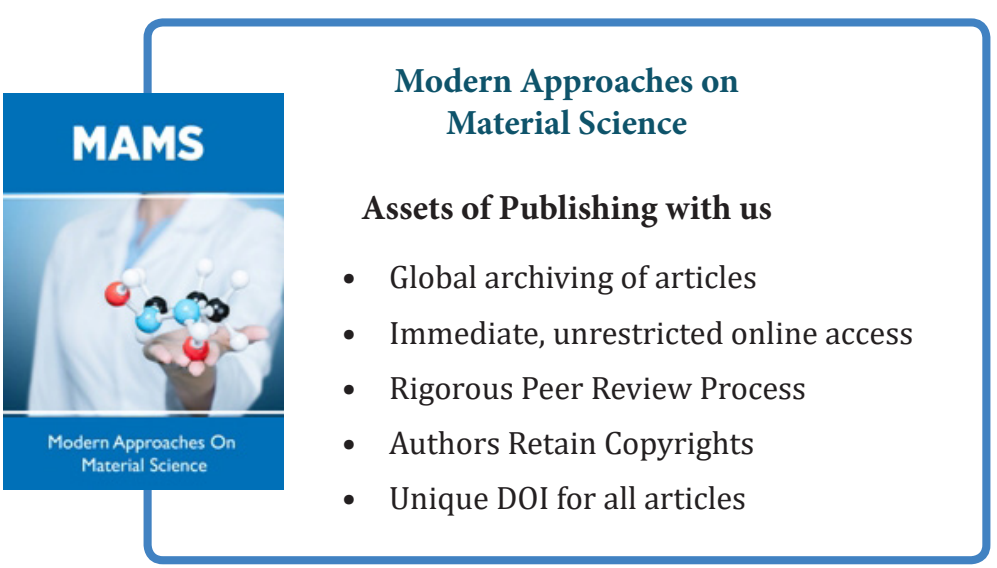

